\title{
Pengaruh Proses Nitriding Terhadap Perubahan Kekerasan Dan Keausan Permukaan Baja St 40 Dengan Variasi Waktu Dan Suhu
}

\author{
Trisbenheiser $^{1 *}$ \\ ${ }^{1}$ Jurusan Teknik Mesin Politeknik Negeri Ujung Pandang, Makassar 90245, Indonesia \\ *email: trisbenheiser@poliupg.ac.id
}

\begin{abstract}
Nitriding is a hardening surface that purpose to upgrading the mechanical properties of steel against the corrosion and the wear and tear. At this research, the nitriding process was conducted with the diffusion of nitride atoms into the specimen surface through the specimen heating process with urea fertilizer as the nitrogen producer. This nitriding process is using the heating temperature variation of 450c, 500c and 550c with time holding variations for 1 hour, 3hours and 5 hours. From the research and examination result, obtained the highest hardness score is $116,30 \mathrm{~kg} / \mathrm{mm} \mathrm{HB}$ at the temperature of $550 \mathrm{c}$ with the length of holding time is 5 hours. And for the material wearness result with the wearing time variation is directly proportional to the specimen hardness value. The result of micro structure specimen examination after being nitrided, showed the raising of perlite value of the specimen, which the more increasing the heating temperature, the more the perlite phase occurred, this is directly proportional with the occur of the diffusion depth.
\end{abstract}

Keywords: Nitriding, St 40 Steel, Urea, Diffusion, Hardness, Wear and Tear, Micro Structure

\begin{abstract}
Abstrak: Nitridasi adalah pengerasan permukaan yang bertujuan untuk meningkatkan sifat mekanik baja terhadap korosi serta keausan. Pada penelitian ini, proses nitriding dilakukan dengan mendifusikan atom-atom nitrida ke dalam permukaan spesimen melalui proses pemanasan spesimen dengan pupuk urea sebagai penghasil nitrogen. Proses nitriding ini menggunakan variasi suhu pemanasan $450^{\circ} \mathrm{C}, 500^{\circ} \mathrm{C}$, dan $550^{\circ} \mathrm{C}$ dengan variasi waktu penahanan selama $1 \mathrm{jam}, 3 \mathrm{jam}$, dan 5 jam. Dari hasil penelitian serta pengujian didapatkan nilai kekerasan tertinggi $116,30 \mathrm{~kg} / \mathrm{mm}^{2} \mathrm{HB}$ pada temperatur $550^{\circ} \mathrm{C}$ dengan lama waktu penahanan $5 \mathrm{jam}$. Dan untuk hasil keausan material dengan variasi waktu pengausan berbanding lurus nilai kekerasan spesimen. Hasil pengujian struktur mikro speeimen setelah dinitridasi, menunjukkan kenaikan jumlah perlit pada spesimen, yang mana semakin meningkat suhu pemanasannya maka semakin banyak fasa perlit yang terjadi, hal ini berbanding lurus dengan hasil kedalaman difusi yang terjadi.
\end{abstract}

Kata kunci: Nitridasi; Baja St 40; Urea; Difusi; Kekerasan; Keausan; Struktur mikro

\section{PENDAhuluan}

Baja ialah material yang banyak dipakai pada konstruksi mesin, sebab memiliki sifat ulet, kuat, mampu keras maupun mudah dibentuk. Penggunaan material baja seperti pada roda gigi, poros, dan lain-lain pada proses permesinan selalu berinteraksi dengan material lain sehingga akan mengakibatkan gesekan serta tekanan [1]. Kandungan karbon di dalam struktur baja akan berpengaruh pada sifat mampu keras. Sifat ini dibutuhkan pada komponen-komponen mesin yang selalu bergesekan sebab fungsinya harus memiliki kekerasan tertentu. Kekerasan pada komponen-komponen mesin dari baja, bisa diperoleh melalui teknik pengerasan permukaan. Berbagai cara bisa dilakukan untuk peningkatan kualitas permukaan dari suatu material sesuai kebutuhan produk yang diinginkan. Pada bagian rekayasa material, pengerasan permukaan dikenal dengan nama "perlakuan permukaan".Pengerasan permukaan merupakan metode peningkatan sifat kekerasan dan kinerja dari komponen-komponen atau material.

Beberapa metode ppengerasan permukaan yang biasa dilakukan ialah karburasi (carburizing), nitridasi (nitriding), induksi listrik, karbonitridasi (carbonitriding), dan/serta nyala api [2]. Dari jenisjenis pengerasan permukaan tersebut, pengerasan permukaan yang digunakan pada penelitian ini ialah pengerasan permukaan dengan cara nitriding, ini karena nitriding tidak memerlukan temperatur tinggi untuk menghasilkan permukaan material kuat dan keras, selain itu reaksi unsurunsur nitrogen yang terjadi pada permukaan material juga mempunyai tingkat kekerasan tinggi jika dibandingkan bila menggunakan reaksi karbon. Nitridasi adalah pengerasan permukaan material 
dengan menambahkan unsur-unsur nitrogen pada permukaan material dengan temperature (suhu) dan waktu penahanan tertentu.

Proses nitridasi dipengaruhi oleh temperature (suhu) dan waktu. Semakin tinggi temperature (suhu) pemanasan nitriding maka nilai kekerasannya semakin tinggi/ semakin keras dan semakin dalam nitrogen yang terdifusi pada material. Semakin lama waktu penahanan yang digunakan maka kedalaman lapisan atom-atom nitridanya semakin besar [3]. Beberapa contoh aplikasi material nitridasi seperti peralatan kesehatan untuk alat-alat kedokteran gigi dan alat-alat bedah kedokteran, pipelines, valves, nozzle, spindle, shaft, compressor dan turbine wheels. Pada penelitian sebelumnya, telah dilakukan beberapa metode nitriding yang bertujuan menghasilkan kekerasan permukaan spesimen. Diantaranya teknik nitridasi gas, teknik nitridasi plasma, teknik nitridasi laser, teknik implementasi ion nitridasi, serta teknik nitridasi dengan menggunakan urea. Akan tetapi jika dari sudut pandang teknik, metode nitridasi gas, nitridasi plasma serta implementasi ion mempunyai kelemahan, diantaranya prosesnya rumit serta memerlukan dana yang besar. Pada penelitian ini akan dianalisa perubahan kekerasan dan keausan spesimen yang telah melalui proses nitriding dengan variasi waktu dan suhu. Media yang digunakan sebagai sumber nitrogen adalah pupuk urea. Dimana pupuk urea memiliki kandungan nitrogen sebanyak 46\% [4].

\section{METODOLOGI PENELITIAN}

Penelitian dilakukan kurang lebih selama enam bulan. Adapun tempat pelaksanaan penelitian sebagian di Laboratorium Teknologi Teknik Mesin UKIP Makassar berkaitan dengan proses pembuatan spesimen dan sebagian lagi di Laboratorium Metalurgi Fisik Teknik Mesin UKIP Makassar untuk proses nitriding, proses uji kekerasan, proses analisa struktur mikro, dan proses uji keausan specimen yang diteliti.

Bahan yang digunakan meliputi dua macam yaitu: bahan utama sebagai obyek pengamatan, yang diperoleh pada Toko Besi Gunung Kawi Sakti Makassar dan bahan pendukung kegiatan penelitian. Bahan utama sebagai obyek pengamatan adalah St 40 dengan ukuran diameter $19 \mathrm{~mm}$ serta ketebalan $15 \mathrm{~mm}$. Bahan pendukung yang dipakai dalam penelitian ini adalah pupuk urea sebagai sumber nitrogen. Sedangkan peralatan-peralatan yang digunakan adalah wadah (chamber) dengan dimensi 40 $\mathrm{mm} \times 40 \mathrm{~mm} \times 40 \mathrm{~mm}$, furnance, alat uji kekerasan Brinell merk Ernst type NR3D-DR, alat pengamatan struktur mikro, mesin uji keausan, mesin gerinda tangan, jangka sorong (Vernier Caliper), neraca digital,dan tang penjepit.

Langkah kerja penelitian proses nitridasi terbagi dari beberapa tahap, meliputi Pembuatan wadah (chamber), Pembuatan spesimen, Proses nitriding, dan Pengujian specimen. Alat-alat yang digunakan pada penelitian ini meliputi: mesin gerinda tangan, las listrik, mistar baja, vernier caliper, tang penjepit, neraca digital, dapur pemanas (furnance), mesin uji keausan, alat kekerasan, dan alat uji struktur mikro.

Langkah-langkah kerja tersebut diuraikan sebagai berikut:

1. Pembuatan Wadah (chamber)

Wadah (chamber) dibuat dari plat besi dengan tebal $2 \mathrm{~mm}$. plat dipotong dengan ukuran 40 $\mathrm{mm}$ x $40 \mathrm{~mm}$ x $40 \mathrm{~mm}$ kemudian dibentuk sesuai dengan gambar.

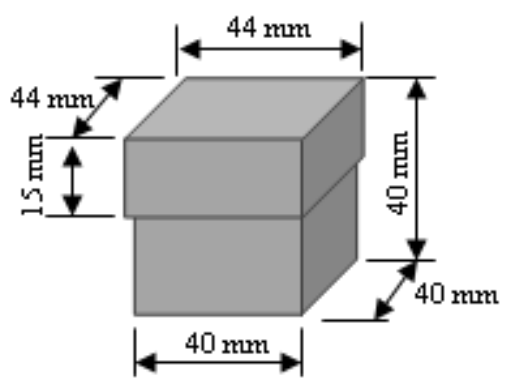

Gambar 1. Skema Wadah Nitridasi 
184 Trisbenheiser. Pengaruh Proses Nitriding Terhadap Perubahan Kekerasan Dan Keausan Permukaan Baja St 40 Dengan Variasi Waktu Dan Suhu

2. Pembuatan Spesimen

Spesimen dipotong menggunakan mesin gerinda tangan dengan ukuran diameter $19 \mathrm{~mm}$ dengan ketebalan $15 \mathrm{~mm}$.

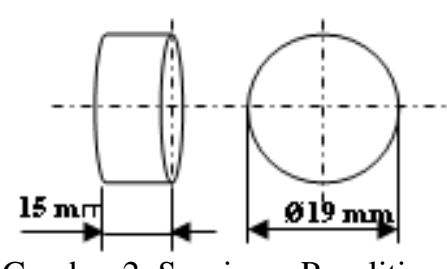

Gambar 2. Spesimen Penelitian

\section{Proses Nitriding}

Spesimen yang hendak dinitridasi diletakkan di dalam wadah (chamber) yang berisi serbuk nitrida [5,6,7] dan kemudian dimasukkan dalam dapur pemanas (furnance) untuk proses nitridasi dengan suhu $450^{\circ} \mathrm{C}, 500^{\circ} \mathrm{C}, 550^{\circ} \mathrm{C}$ [9] dengan lama waktu penahanan $1 \mathrm{jam}, 3 \mathrm{jam}$, dan 5 jam [10].

4. Pengujian Spesimen

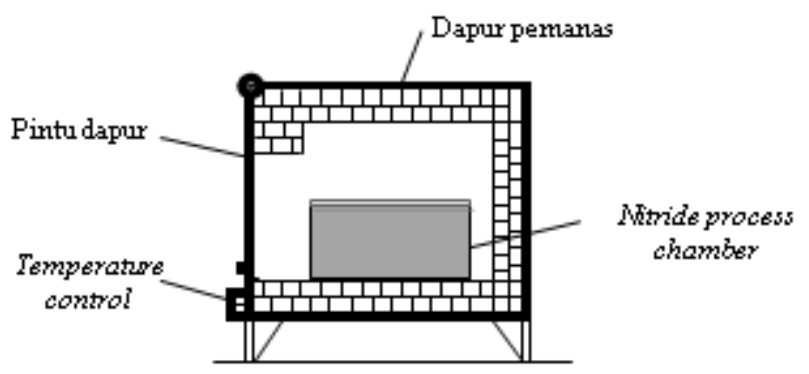

Setelah proses nitridasi kemudian dilakukan pengujian kekerasan, pengujian keausan, dan pengujian struktur mikro. Pengujian kekerasan dilakukan dalam 8 (delapan) tahap pengujian. Pengujian kekerasan dilakukan mulai dari tebal spesimen $15 \mathrm{~mm}$ (permukaan spesimen), 14,3 mm, 13,6 mm, 12,9 mm, 12,2 mm, 11,5 mm, 10,8 mm, dan 10,1 mm dengan metode Brinell. Diameter indentor yang dipakai $1,588 \mathrm{~mm}$ dan beban penekanan $60 \mathrm{~kg}$. Pengujian laju keausan dilakukan dengan metode pin on abrasive disc [11] dan mengacu pada standar ASTM (ASTM, G99,203). Beban yang diberikan sebesar 10N, putaran 258,2 rpm dengan variasi waktu pengausan 60 menit, 90 menit, dan 120 menit untuk spesimen yang telah mengalami proses nitriding dan 60 menit untuk spesimen tanpa perlakuan (raw material). Ukuran abrasive paper yang dipakai ialah 120 $\mathrm{cw}[12]$.

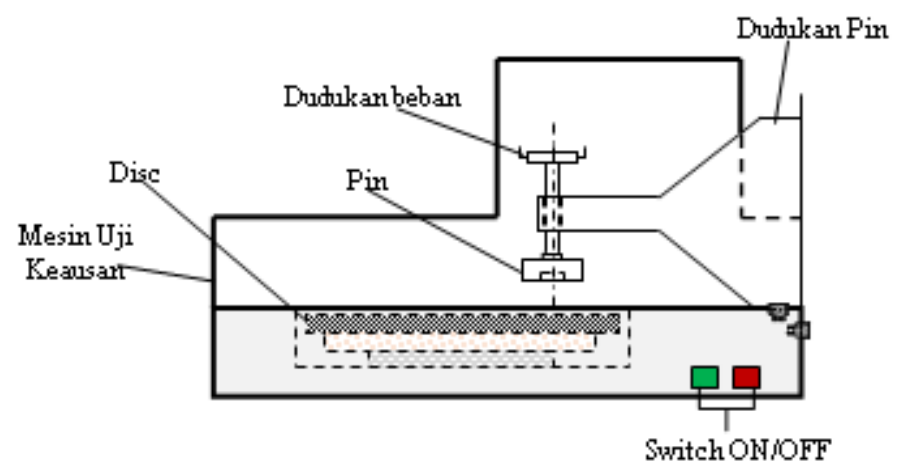

Gambar 4. Skema Mesin Uji Keausan 
Laju keausan dinyatakan dengan persamaan (1) [8]

Keterangan:

$$
W=\frac{V_{i}-V_{f}}{t}=\frac{\Delta V}{t} \ldots \ldots
$$

$\mathrm{W}=$ Laju keausan $\left(\mathrm{mm}^{3} / \mathrm{menit}\right)$

$\Delta \mathrm{V} \quad=$ Volume yang terabrasi $\left(\mathrm{mm}^{3}\right)$

$\mathrm{Vi} \quad=$ Volume awal spesimen $\left(\mathrm{mm}^{3}\right)$

Vf $=$ Volume akhir spesimen setelah pengausan $\left(\mathrm{mm}^{3}\right)$

$\mathrm{t} \quad=$ waktu pengausan (menit)

Analisa struktur mikro dilakukan untuk mendukung analisa data nilai kekerasan dan juga untuk melihat perubahan struktur mikro spesimen sebelum dan sesudah dinitridasi dengan pupuk nitrogen (urea).

Adapun spesimen pengujian penelitian ini, berdasarkan tabel di bawah ini:

Tabel 1. Spesimen pengujian

\begin{tabular}{|c|c|c|c|c|}
\hline No & Spesimen & $\begin{array}{c}\text { Pengujian } \\
\text { Kekerasan }\end{array}$ & $\begin{array}{c}\text { Pengujian } \\
\text { Keausan }\end{array}$ & $\begin{array}{c}\text { Pengujian Struktuur } \\
\text { mikro }\end{array}$ \\
\hline 1 & Raw material & 1 & 1 & 1 \\
\hline 2 & $450^{\circ} \mathrm{C}$ & 3 & 9 & 3 \\
\hline 3 & $500^{\circ} \mathrm{C}$ & 3 & 9 & 3 \\
\hline 4 & $550^{\circ} \mathrm{C}$ & 3 & 9 & 3 \\
\hline
\end{tabular}

\section{HASIL DAN PEMBAHASAN}

\section{A. Foto Spesimen Hasil Nitriding}

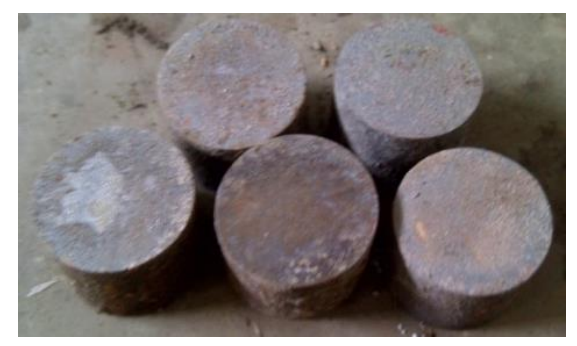

Gambar 5. Spesimen hasil nitriding

\section{B. Analisa Hasil Pengujian Kekerasan}

Dari hasil pengujian kekerasan pada spesimen tanpa perlakuan (raw material) dan spesimen yang telah melalui proses nitridasi terlihat bahwa nilai kekerasan pada raw material sebesar 106,65 $\mathrm{kg} / \mathrm{mm}^{2}$ skala $\mathrm{HB}$ dan pada spesimen dengan perlakuan nilai kekerasan yang paling tinggi terdapat pada temperatur $550^{\circ} \mathrm{C}$ dengan tebal $15 \mathrm{~mm}$ (permukaan spesimen) yakni:

D Baja ST 40 Nitridai T: $550^{\circ} \mathrm{C}(1 \mathrm{jam}): 115,46 \mathrm{~kg} / \mathrm{mm}^{2} \mathrm{HB}$

Baja ST 40 Nitridasi T: $550^{\circ} \mathrm{C}(3 \mathrm{jam}): 116,30 \mathrm{~kg} / \mathrm{mm}^{2} \mathrm{HB}$

Baja ST 40 Nitridasi T $550^{\circ} \mathrm{C}(5 \mathrm{jam}): 116,51 \mathrm{~kg} / \mathrm{mm}^{2} \mathrm{HB}$

Hal ini disebabkan karena pada daerah dengan tebal $15 \mathrm{~mm}$ (permukaan spesimen), konsentrasi atom-atom nitrogen yang terdifusi ke dalam spesimen akan lebih besar bila dibandingkan daerah dengan ketebalan yang lain. Semakin ke dalam, konsentrasi atom nitrogen yang terdifusi secara intertisi ke dalam spesimen akan semakin menurun atau sedikit. 
186 Trisbenheiser. Pengaruh Proses Nitriding Terhadap Perubahan Kekerasan Dan Keausan Permukaan Baja St 40 Dengan Variasi Waktu Dan Suhu

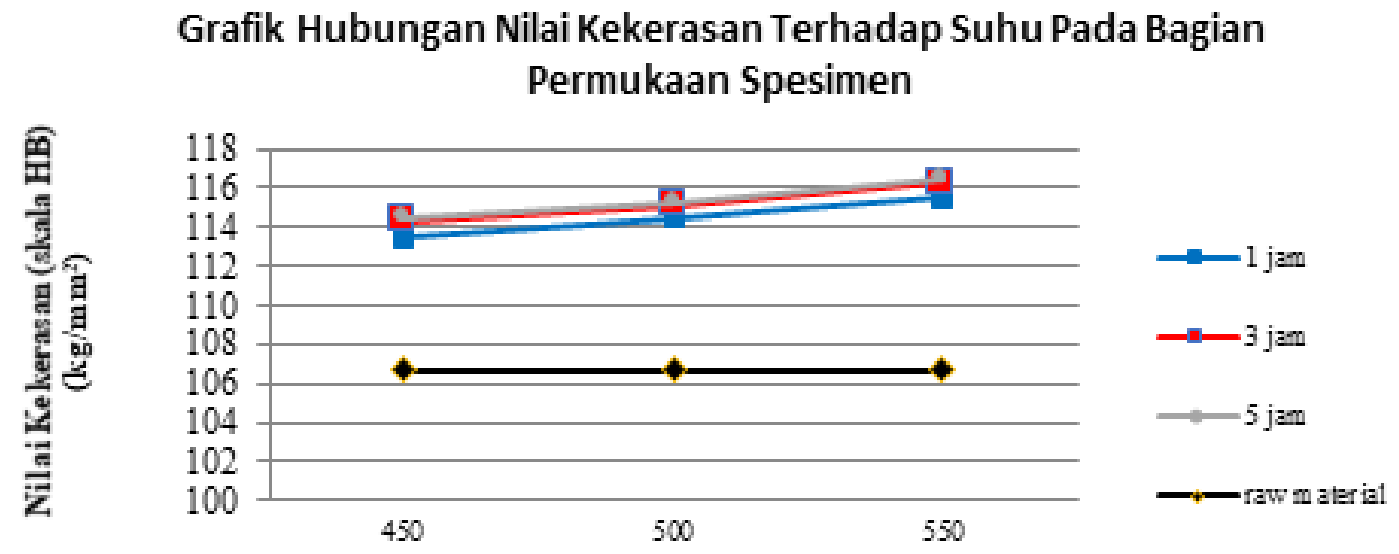

Suhu $\left({ }^{\circ} \mathrm{C}\right)$

Gambar 5. Grafik Hubungan Nilai Kekerasan terhadap Suhu Pada Bagian Permukaan Spesimen (15 mm).

\section{Analisa Hasil Pengujian Keausan}

Dari hasil pengujian, diketahui bahwa keausan pada spesimen dasar untuk waktu pengausan ( $t$ ) 60 menit adalah $4,16 \mathrm{~mm}^{3} /$ menit dan keausan pada spesimen setelah perlakuan bisa dilihat pada tabel berikut:

Tabel 2. Laju Keausan, putaran disc (258,2 rpm), abrasive paper (120 cw)

\begin{tabular}{|c|c|c|c|c|c|c|}
\hline \multirow{2}{*}{$\begin{array}{l}\text { Suhu } \\
\left({ }^{\circ} \mathrm{C}\right)\end{array}$} & \multirow{2}{*}{$\begin{array}{l}\mathrm{HT} \\
\text { (jam) }\end{array}$} & \multirow{2}{*}{$\begin{array}{l}\text { Beban } \\
(\mathrm{N})\end{array}$} & \multicolumn{3}{|c|}{ Waktu (menit) } & \multirow{2}{*}{$\begin{array}{c}\text { Rata-rata } \\
\left(\mathrm{mm}^{3} / \text { menit }\right)\end{array}$} \\
\hline & & & 60 & 90 & 120 & \\
\hline \multirow{3}{*}{450} & 1 & \multirow{9}{*}{10} & $1,23 \mathrm{~mm}^{3} /$ menit & $1,39 \mathrm{~mm}^{3} /$ menit & $1,61 \mathrm{~mm}^{3} /$ menit & 1,41 \\
\hline & 3 & & $1,13 \mathrm{~mm}^{3} /$ menit & $1,26 \mathrm{~mm}^{3} /$ menit & $1,42 \mathrm{~mm}^{3} /$ menit & 1,27 \\
\hline & 5 & & $1,04 \mathrm{~mm}^{3} /$ menit & $1,20 \mathrm{~mm}^{3} /$ menit & $1,23 \mathrm{~mm}^{3} /$ menit & 1,16 \\
\hline \multirow{3}{*}{500} & 1 & & $0,94 \mathrm{~mm}^{3} /$ menit & $1,01 \mathrm{~mm}^{3} /$ menit & $1,09 \mathrm{~mm}^{3} /$ menit & 1,01 \\
\hline & 3 & & $0,76 \mathrm{~mm}^{3} /$ menit & $0,88 \mathrm{~mm}^{3} /$ menit & $0,94 \mathrm{~mm}^{3} /$ menit & 0,86 \\
\hline & 5 & & $0,66 \mathrm{~mm}^{3} /$ menit & $0,76 \mathrm{~mm}^{3} /$ menit & $0,80 \mathrm{~mm}^{3} /$ menit & 0,74 \\
\hline \multirow{3}{*}{550} & 1 & & $0,57 \mathrm{~mm}^{3} /$ menit & $0,63 \mathrm{~mm}^{3} /$ menit & $0,71 \mathrm{~mm}^{3} /$ menit & 0,64 \\
\hline & 3 & & $0,47 \mathrm{~mm}^{3} /$ menit & $0,50 \mathrm{~mm}^{3} /$ menit & $0,66 \mathrm{~mm}^{3} /$ menit & 0,54 \\
\hline & 5 & & $0,38 \mathrm{~mm}^{3} /$ menit & $0,44 \mathrm{~mm}^{3} /$ menit & $0,57 \mathrm{~mm}^{3} /$ menit & 0,46 \\
\hline
\end{tabular}

\section{Analisa Struktur Mikro}

Hasil analisa struktur mikro dengan pembesaran $100 \mathrm{X}$ bisa dilihat pada gambar di bawah ini:

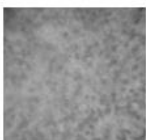

(a)

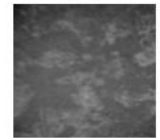

(c)

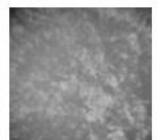

(b)

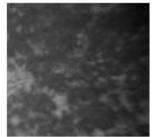

(d)

Gambar 3. Struktur mikro baja ST 40 (a) sebelum nitridasi, (b) nitridasi T: $450^{\circ} \mathrm{C}$, (c) nitridasi $\mathrm{T}: 500^{\circ} \mathrm{C}$, (d) nitridasi $\mathrm{T}: 550^{\circ} \mathrm{C}$. 
Dari hasil Analisa struktur mikro yang terbentuk pada spesimen, terdapat perbedaan antara spesimen tanpa perlakuan dengan spesimen yang sudah melalui proses nitridasi dengan variasi waktu dan suhu (temperatur) dalam bubuk urea. Dari foto struktur mikro, spesimen tanpa perlakuan terlihat fasa ferit (white) mendominasi permukaan spesimen apabila dibandingkan dengan fasa perlit (dark). Ini memperlihatkan bahwa spesimen ini mempunyai sifat keuletan yang tinggi tetapi mempunyai nilai kekerasan rendah. Sementara pada spesimen uji yang sudah melalui perlakuan, terlihat fasa perlit mulai terjadi akibat pendifusian atom-atom nitrogen pada spesimen menyebabkan tumbuhnya fasa austenit. Akibat proses pendinginan lambat maka austenit ini bertransformasi menjadi perlit, sehingga dapat membuktikan analisa kenaikan nilai kekerasan pada bagian permukaan spesimen. Perlit yang terbentuk mempunyai sifat kekerasan yang lebih bagus jika dibandingkan dengan ferlit, dimana perlit mempunyai sifat kekerasan, ketangguhan, dan ketahanan tinggi pada faktor korosi.

\section{KESIMPULAN}

\section{Kesimpulan}

Dari hasil penelitian serta analisa pengujian serta pembahasan data, maka dapat disimpulkan bahwa

1. Peningkatan waktu penahanan dan suhu pada proses nitriding memberikan pengaruh terhadap peningkatan kekerasan permukaan pada spesimen dimana semakin tinggi temperatur (suhu) dan semakin lama waktu penahanan saat proses nitriding, mengakibatkan perubahan kekerasan pada bagian permukaan baja St 40 akan semakin meningkat. Nilai kekerasan tertinggi terjadi pada suhu $550^{\circ} \mathrm{C}$ dengan waktu penahanan 5 jam dimana nilai kekerasannya adalah 116,51 $\mathrm{HB}$ pada bagian permukaan spesimen.

2. Dari hasil analsia struktur mikro spesimen yang sudah melalui proses Nitriding dengan variasi waktu, dan suhu terlihat fasa perlit pada bagian permukaan mulai terjadi. Semakin meningkat suhu serta semakin lama waktunya maka fasa perlit yang tercipta makin banyak. Fasa perlit yang tercipta memiliki sifat kekerasan yang baik daripada fasa ferit.

3. Dari hasil pengujian laju keausan diperoleh nilai laju keausan raw material sebesar $4,16 \mathrm{~mm}^{3} / \mathrm{menit}$ pada waktu pengausan 60 menit. Penambahan waktu tahan dan suhu pada proses nitriding juga memberi pengaruh terhadap laju keausan permukaan pada baja $\mathrm{St} 40$ dimana nilai laju keausan terkecil setelah proses nitriding sebesar $0,38 \mathrm{~mm}^{3} /$ menit pada suhu $550^{\circ} \mathrm{C}$ dengan waktu penahanan 5 jam untuk waktu pengausan 60 menit dan untuk waktu pengausan 90 menit dan 120 menit, nilai laju keausan terkecil sebesar $0,44 \mathrm{~mm}^{3} /$ menit dan $0,57 \mathrm{~mm}^{3} /$ menit pada suhu $550^{\circ} \mathrm{C}$ dengan waktu penahanan 5 jam.

\section{Saran}

Pada penelitian selanjutnya yang sejenis sebaiknya dilakukan dengan menggunakan variasi sumber nitrogennya.

\section{DAFTAR PUSTAKA}

[1] Haqi, M.I. 2006. "Hardening Pada Baja Karbon Tinggi". https://slideshare.net/handryseptia/file4433398146f4f/. Diakses pada tanggal 31 Juli 2015.

[2] A.,J., Sukma. 2012. Pengerasan Permukaan Baja Karbon ST 40 Dengan Metode Nitridasi Dalam Larutan Kalium Nitrat. Semarang: Universitas Diponegoro. Thesis.

[3] Furqon, Muhammad dkk. 1997. Pengaruh Temperatur dan waktu penahanaan terhadap ketebalan dan kekerasan lapisan permukaan hasil nitriding cair baja paduan rendah $\mathrm{Cr}-\mathrm{Ni}$ untuk tabung hidrolik. Prosiding pertemuan ilmiah sains materi 1997. ISSN: 1410-2897, hlm. $114-119$.

[4] Sulthon, Febriyan N. Nur. 2014. Pengaruh variasi holding time dan variasi jenis pupuk nitrogen terhadap ketahanan aus baja aisi 304 dengan metode pack nitriding. Malang: Universitas Negeri Malang. Thesis.

[5] Elviyenti. 2010. Pengaruh Nitridasi Terhadap Laju Korosi Stainless Steel AISI 316L Dengan Metode Pack Nitriding. Padang: Universitas Andalas. Thesis. 
188 Trisbenheiser. Pengaruh Proses Nitriding Terhadap Perubahan Kekerasan Dan Keausan Permukaan Baja St 40 Dengan Variasi Waktu Dan Suhu

[6] E., Sulistyo, Y., Sudana. 2010. Proses Pack Nitriding Dengan Variasi Suhu dan Media Pupuk Nitrogen Terhadap Kekerasan AISI 420. Jurnal Rekayasa Mesin Vol. 1, No. 1, hlm. 17-20.

[7] B.A., Setiawam, W. Purwadi. 2009. Pengaruh Temperatur Dan Waktu Proses Nitridasi Terhadap Kekerasan Permukaan FCD 700 Dengan Media Nitridasi Urea. Seminar Nasional Kluster Riset Teknik Mesin, hlm. 35-40.

[8] V. Malau, Khasani. 2008. Karakterisasi Laju Keausan Dan Kekerasan Dari Pack Carburizing Pada Baja Karbon AISI 1020. Jurnal Media Teknik No. 3 Tahun XXX, hlm. 367-374.

[9] Y., Umardhani. 2011. Pengerasan Permukaan Baja Karbon ST 40 Dengan Metode Nitridasi Dalam Larutan Garam. Rotasi-Vol. 13, No. 4, hlm. 20-23.

[10] Warsito, J.K., Nugroho. 2014. Peningkatan Sifat Mekanis Baja Karbon Rendah Melalui Metode Nitrocarburizing DC Plasma. Prosiding Seminar Nasional Aplikasi Sains \& Teknologi (SNAST). ISSN: 1979-911X, hlm. 31-34.

[11] Zulfikar. 2010. Studi Sifat Fisis Dan Mekanis Komposit Aluminium / Fly Ash Dengan Variasi Fraksi Berat Dan Temperatur Sintering. Jurnal Teknik Mesin Vol. 7, No. , hlm. 106 - 113.

[12] Y. Umardani, M., Bukori. 2007. Karakterisasi Material Ball Mill Pada Proses Pembuatan Semen Dengan Metoda Pengujian Kekerasan, Mikrigrafi dan Keausan. Rotasi-Vol. 9, No. 4, hlm. 32-35. 